\title{
DETERMINING OPTIMAL DESIGNS OF TIMBER BEAMS WITH NON-UNIFORM CROSS-SECTION
}

\author{
PRIMOŽ JELUŠIČ \\ Faculty of Civil Engineering, Transportation Engineering and Architecture, University of Maribor, Slovenia
}

\begin{abstract}
The paper presents an optimal design of timber beams with non-uniform cross-section based on multiparametric mixed-integer non-linear programming (MINLP) optimization and Response Surface Optimization (RSO). For this purpose, the optimization model was developed with integrated requirements of Eurocode specifications. In order to get the variation of a given performance with respect to input parameters, the response surface optimization was performed as part of a finite element analysis. Using the deterministic analysis, we have been able to investigate the performance of the design over continuous ranges of the input parameters, using a limited number of simulations. From the response surface, we are able to identify the key parameters really influencing the design. In order to interpret the applicability of the response surface optimization and the recommended optimal design for the timber beam with non-uniform cross-section, the paper presents an example of determining the cheapest possible structure for the given design parameters.

Keywords: timber beam, finite element analysis, structural optimization, mixed-integer non-linear programming, response surface optimization.
\end{abstract}

\section{INTRODUCTION}

In order to tailor the size of the beam to the force distribution or to obtain suitable geometry and architecturally attractive design the beams cross-section are designed to be non-uniform. Loading a timber beam with non-uniform cross-section in bending will result in stresses both perpendicular and parallel to the beam. The normal stresses at the concave side are generally larger than the normal stresses in the convex side. In practical design of timber structures several basic types of beams with non-uniform cross-section are used: curved beam, tapered beam, double tapered beam. The combined tapered beam with curved underside is also used because of practical reasons. Fig. 1 shows the curved beam, double tapered beam and tapered beam with curved underside.

According to Eurocode 5 [1], the fundamental requirements of structural design and principles for safety and serviceability are nearly the same as for the straight beams. However, the bending, tension and compression strength of timber should be modified with respect to curvature $(1 / r)$ and a lamella thickness $(t)$. The production of glulam curved beams with large span is relative simple, but with increasing span the lateral instability and buckling are likely to occur. In order to reduce the out-of-plane instability problems the three-hinged arch with curved or sharp corners are used (Fig. 1). In this paper the MINLP optimization model for an optimal design of double tapered beam is presented. Moreover, the finite element analysis with combined response surface optimization (RSO) was used in order to investigate the performance of the design over continuous ranges of the input parameters.

In order to develop the high-performance structures, the new composites materials [1][6] and new concepts of design are required [7]-[10]. In the recent past, various methods and algorithms have been applied for the optimization of structures. The MINLP optimization method has frequently been used in structural design [11], [12]. 


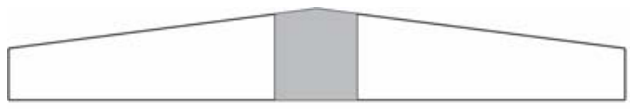

(a)

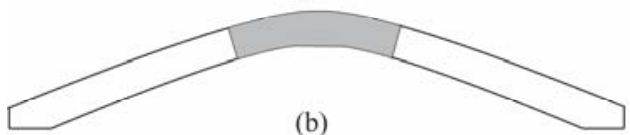

(b)

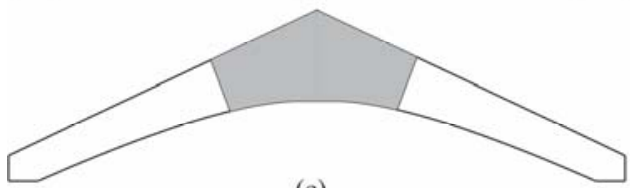

(c)

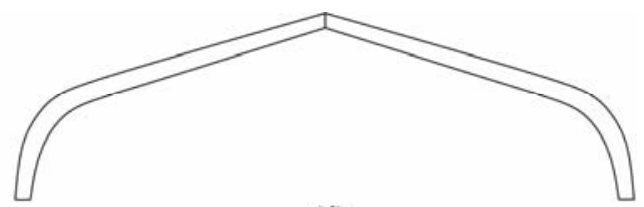

(d)

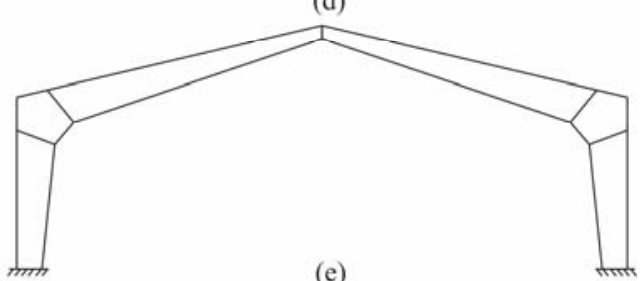

Figure 1: Beams and frames. (a) Double tapered beam; (b) Curved beam; (c) Combined tapered beam with curved underside; (d) and (e) Three-hinged arch.

\section{OPTIMIZATION ALGORITHMS}

Two different approaches for the optimization of timber beams were used. The mixed-integer non-linear programming (MINLP) was used to obtain the practical engineering design of laminated timber beam, while the response surface optimization was used to investigate the performance of the design over continuous ranges of the input parameters. The MINLP problem was solved by using the computer program DICOPT [13], which is based on Outer Approximation, Equality Relaxation and Augment Penalty. The DICOPT starts by solving the nonlinear programs (NLP) where the $0-1$ conditions on the binary variables are relaxed. If the optimal solution to this problem yields an integer solution the search stops. Otherwise, it continues with an alternating sequence of NLP called sub-problems and mixed-integer linear programs (MIP) called master problems. The NLP sub-problems are solved for fixed $0-1$ variables that are predicted by the MIP master problem at each iteration.

Design optimization as part of a finite element analysis consists of input variables, constraints, and an objective. The aim of a design optimization is to determine values for the input variables that will meet the design objective, while staying within the constraints.

Response Surface Optimization (RSO) requires that the design point results are generated before the optimization. The design point configurations are typically determined using Design of Experiments (DOE) methods with the intent of characterizing the system response using a minimum number of actual analysis runs. Several tasks are performed during the analysis and optimization: a) define design variables, objectives and constraints b) determine the potential trade-offs between objectives, c) determine the optimization method, d) perform the sensitivity analysis. In order to perform the sensitivity analysis the response surface is build. In this way, the influence of each variable on the objective function is determined.

\section{MINLP OPTIMIZATION MODEL OF DOUBLE TAPERED BEAM}

The optimization model of tapered glulam beam contains the cost objective function which is subjected to structural analysis and dimensioning constraints. The conditions were defined in accordance with Eurocode standard which ensures that ultimate limit state and serviceability limit states are satisfied. The cost of timber beam is calculated with eqn (1):

$$
\operatorname{COST}=c_{\text {tim }} \cdot L \cdot\left(h_{\min }+h_{a p}\right) \cdot b / 2 \text {, }
$$


where $L(m)$ is the span of the beam, $h_{\min }(\mathrm{mm})$ is the height of beam at the support, $\mathrm{h}_{\mathrm{ap}}(\mathrm{mm})$ is the height of beam at the middle of the span and b $(\mathrm{mm})$ is the width of the beam.

Five different conditions have been defined in the form of five inequality constraints (eqns (2)-(6)), which were integrated into the optimization model:

Condition 1: The shear stress at the support needs to be less than shear strength of the timber

$$
\mathrm{A}_{0, \text { prov }} \geq \frac{3}{2} \cdot \frac{V_{z d, \max }}{f_{v d}}
$$

Condition 2: The normal stresses at the middle of the beam and at the critical location need to be lower than bending strength

$$
\sigma_{\mathrm{m}, \mathrm{d}} \leq k_{r} \cdot f_{m, d}
$$

Condition 3: The tensile stress perpendicular to the grain needs to be lower than bending strength

$$
\frac{\sigma_{\mathrm{t}, 90, \mathrm{~d}}}{\mathrm{f}_{\mathrm{t}, 90, \mathrm{~d}}} \leq k_{d i s} \cdot\left(\frac{V_{r e f}}{V}\right)^{0.2}
$$

Condition 4: The calculated instantaneous deflection of floor $u_{\text {inst }}$ is lower than a recommended value, see eqn (5)

$$
\frac{M_{y} \cdot L^{2}}{9.6 \cdot E_{0, \text { mean }} \cdot I_{y, \min }} \cdot k_{\sigma}+k_{\tau} \cdot \frac{1.2}{G_{\text {mean }} \cdot A_{\min }} \cdot 2 \cdot \int_{0}^{L / 2}\left(\frac{(g+q) \cdot L}{2}-(g+q) \cdot x\right) \cdot 0.5 \cdot d x \leq \frac{L}{300} .
$$

Condition 8: The calculated final deflection of the beam should be lower than a recommended value, see eqn (6)

$$
\mathrm{u}_{\mathrm{g}, \text { inst }} \cdot\left(1+\mathrm{k}_{\mathrm{def}}\right)+\mathrm{u}_{\mathrm{q}, \text { inst }} \cdot\left(1+\Psi_{2} \cdot \mathrm{k}_{\mathrm{def}}\right) \leq \frac{\mathrm{L}}{200} .
$$

Structural analysis and dimensioning (in)equality constraints also determine the tapered glulam beam dimensions to be calculated inside the defined limits.

\subsection{Sensitivity analysis of MINLP optimization model}

In order to obtain optimal manufacturing costs and designs of the double tapered timber beam, the parametric MINLP optimization was performed for 8 combinations between the following different design parameters:

- 4 different structure spans: $10 \mathrm{~m}, 15 \mathrm{~m}, 20 \mathrm{~m}, 25 \mathrm{~m}$ and

- 2 different imposed loads: $1 \mathrm{kN} / \mathrm{m}^{2}$ and $2 \mathrm{kN} / \mathrm{m}^{2}$.

The material unit prices and other input data for structural analysis of double tapered timber beam are presented in Table 1 . The recommended optimal design for glulam timber beam is determined on the basis of the performed multi-parametric MINLP optimization (Table 2). Fig. 2 shows the self-manufacturing costs of the timber beam structures for different imposed loads $q_{k}$. 
Table 1: The input data for the MINLP optimization model optimal results of timber beam.

\begin{tabular}{|l|c|l|}
\hline Symbol & Value & Description \\
\hline e $(\mathrm{m})$ & 4 & Spacing between floor beams \\
\hline$g_{k}\left(\mathrm{kN} / \mathrm{m}^{2}\right)$ & 1 & Load of timber beams plus floor deck \\
\hline$\gamma_{g}$ & 1.35 & Partial factors for permanent actions \\
\hline$\gamma_{q}$ & 1.50 & Partial factors for imposed actions \\
\hline$\gamma_{M}$ & 1.25 & Partial factor for material properties \\
\hline$\psi_{2}$ & 0 & Factor for the quasi-permanent value of the variable action \\
\hline$f_{m k}(\mathrm{MPa})$ & 30 & Timber flexural strength \\
\hline$f_{v k}(\mathrm{MPa})$ & 2.6 & Shear strength of the timber \\
\hline$f_{t 90 k}(\mathrm{MPa})$ & 0.45 & Timber tensile strength \\
\hline$f_{c 90 k}(\mathrm{MPa})$ & 5.7 & Compression strength of the timber \\
\hline$E c m(\mathrm{MPa})$ & 12500 & Modulus of elasticity of the timber \\
\hline$G_{m e a n}(\mathrm{MPa})$ & 780 & Shear modulus \\
\hline$k_{\text {dis }}$ & 1.4 & Distribution factor \\
\hline$k_{\text {def }}$ & 0.8 & Deformation factor \\
\hline$k_{\text {mod }}$ & 0.8 & Modification factor \\
\hline$V_{\text {ref }}\left(\mathrm{m}^{3}\right)$ & 0.01 & The reference volume for glulam \\
\hline$c_{\text {tim }}\left(€ / \mathrm{m}^{3}\right)$ & 500 & Unit price of glulam \\
\hline
\end{tabular}

Table 2: The optimal results of tapered timber beam, for load $q_{k}=1 \mathrm{kN} / \mathrm{m}^{2}$ and load $q_{k}=2 \mathrm{kN} / \mathrm{m}^{2}$.

\begin{tabular}{|l|c|c|c|c|}
\hline \multicolumn{5}{|c|}{ Load: $q_{k}=1 \mathrm{kN} / \mathrm{m}^{2}$} \\
\hline$L(\mathrm{~m})$ & 10 & 15 & 20 & 25 \\
\hline$h_{\min }(\mathrm{mm})$ & 550 & 600 & 700 & 650 \\
\hline$h_{a p}(\mathrm{~mm})$ & 750 & 1100 & 1350 & 1700 \\
\hline$b(\mathrm{~mm})$ & 100 & 140 & 180 & 220 \\
\hline COST $(\boldsymbol{€})$ & $\mathbf{3 2 5}$ & $\mathbf{8 9 3}$ & $\mathbf{1 8 4 5}$ & $\mathbf{3 2 3 1}$ \\
\hline \multicolumn{5}{|c|}{ Load: $q_{k}=2 \mathrm{kN} / \mathrm{m}^{2}$} \\
\hline$L(\mathrm{~m})$ & 10 & 15 & 20 & 25 \\
\hline$h_{\min }(\mathrm{mm})$ & 700 & 750 & 800 & 850 \\
\hline$h_{a p}(\mathrm{~mm})$ & 850 & 1150 & 1500 & 1800 \\
\hline$b(\mathrm{~mm})$ & 120 & 160 & 200 & 240 \\
\hline COST $(\boldsymbol{€})$ & $\mathbf{4 6 5}$ & $\mathbf{1 1 4 0}$ & $\mathbf{2 3 0 0}$ & $\mathbf{3 9 7 5}$ \\
\hline
\end{tabular}




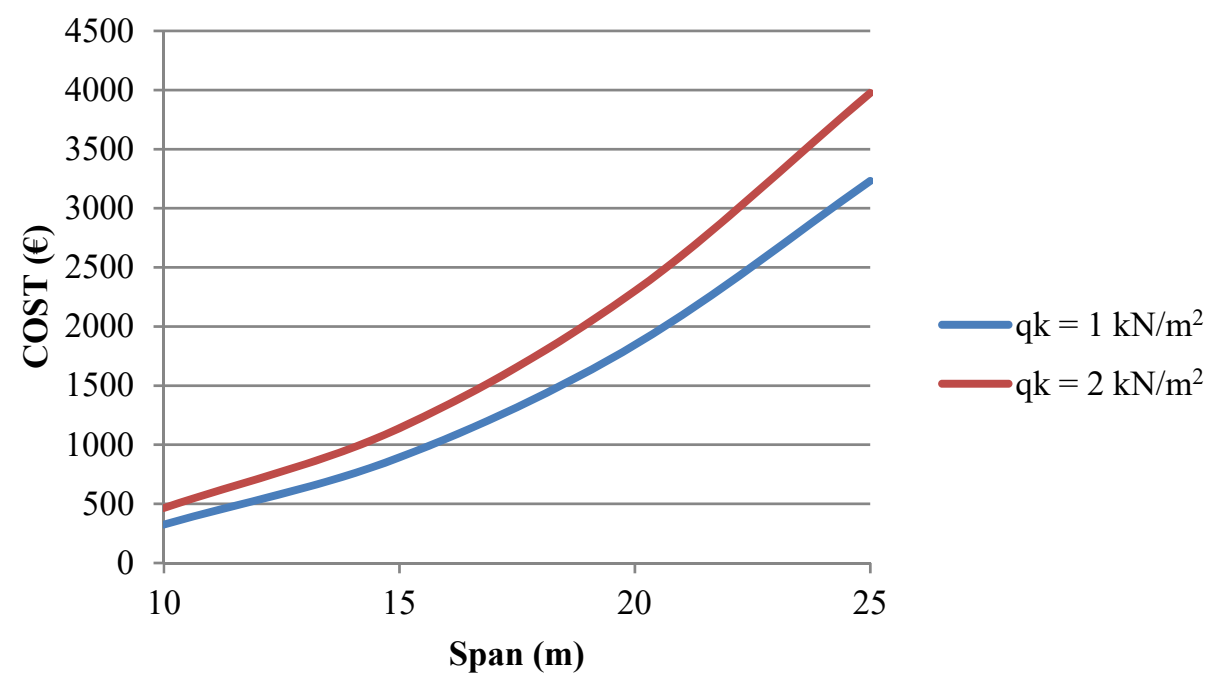

Figure 2: The self-manufacturing costs of the timber beam structures for different imposed loads.

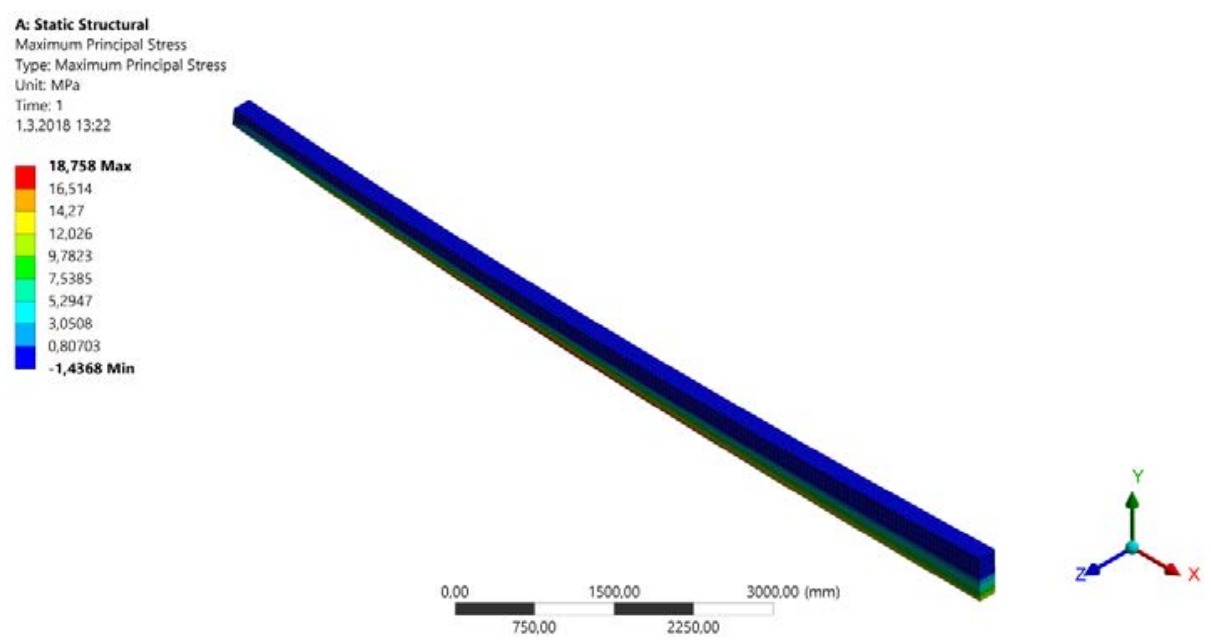

Figure 3: The distribution of normal stress in the glulam beam.

\section{RESPONSE SURFACE OPTIMIZATION}

The optimization of the timber beam was performed by using the response surface optimization and the finite element analysis. The influence of independent variables on dependent responses can be better understood by examining the contour plots which were generated in FE program. Fig. 3 shows the normal stresses distribution in the glulam beam. The optimal results obtained with RSO are presented in Table 3. The 3D tradeoff chart represents the generated samples along with feasible and infeasible points (Fig. 4). 
Table 3: The optimal result obtained with RSO.

\begin{tabular}{|l|c|l|}
\hline Symbol & Value & Description \\
\hline H0 & 688.05 & Height of beam at the support $(\mathrm{mm})$ \\
\hline HA & 1446.4 & Height of beam at the middle $(\mathrm{mm})$ \\
\hline B0 & 200 & Width of the beam $(\mathrm{mm})$ \\
\hline Solid mass & 853.76 & Mass of the beam $(\mathrm{kg})$ \\
\hline C1 & 4.9336 & Maximum shear stress $(\mathrm{MPa})$ \\
\hline C2 & 2.5898 & Maximum principal stress $(\mathrm{MPa})$ \\
\hline C3 & 50.915 & Maximum total deformation $(\mathrm{mm})$ \\
\hline
\end{tabular}

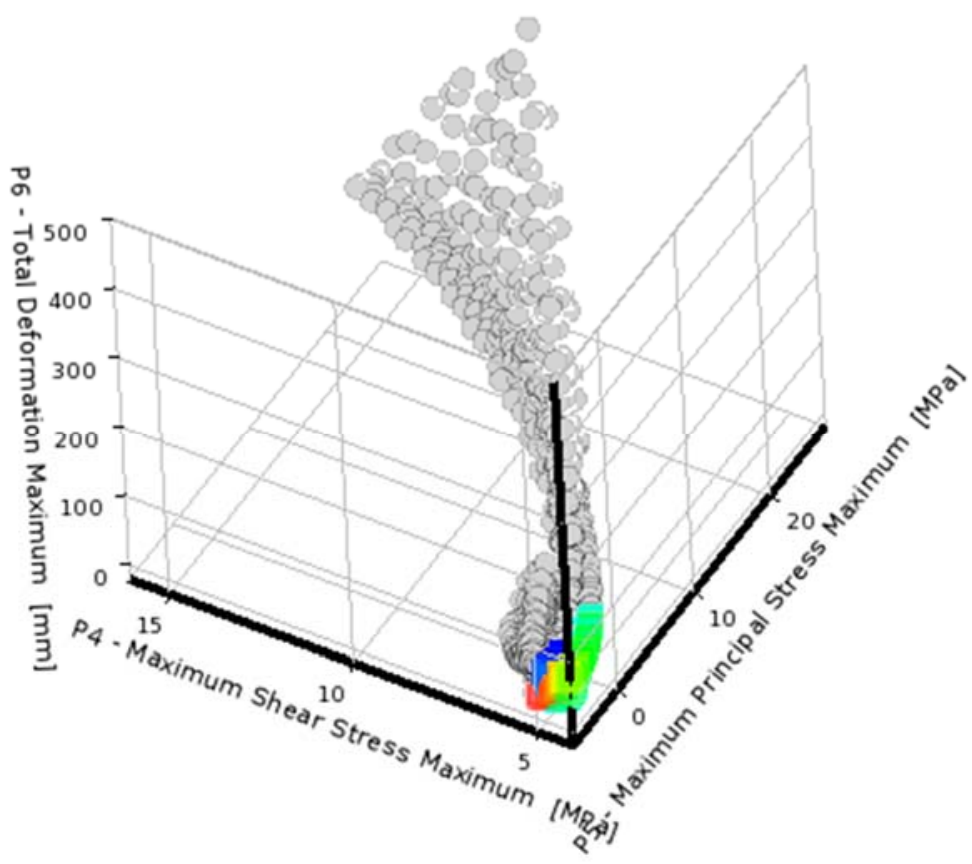

Figure 4: The trade-off chart along with infeasible and feasible points.

\section{CONCLUSION}

The paper presents the cost optimization of a double tapered glulam beam. The optimization was performed by the mixed-integer non-linear programming (MINLP) approach. The MINLP optimization model was thus developed. As the model was developed in a general form, the optimization of the timber floor joists can be performed for different economic conditions and different design parameters. The finite element method with combined response surface optimization was also used to obtain the optimal results. The results were analyzed and compared. A comparison based on structural optimization is much more efficient than one based on the classical structural analysis, because the optimization enables the conditions of both the ultimate and the serviceability limit states of Eurocodes to be fully exploited with no reserve of resistances. It was found that separate analysis for serviceability and ultimate limit state should be preformed when using finite element method and RSO. 


\section{ACKNOWLEDGEMENTS}

Funding for this research was provided by the Slovenian Research Agency and the Ministry of Higher Education, Science and Technology of the Republic of Slovenia, National research program P2-0129.

\section{REFERENCES}

[1] Ivanič, A., Lubej, S. \& Radosavljević, M., Bond improvement in cement mortars reinforced with carbon-fibre composite strands. Proceedings of the 1st International Conference on Structures and Architecture, pp. 1978-1985, 2010.

[2] Ivanič, A., Lubej, S., Rudolf, R. \& Anžel, I., Bond behavior of carbon-fiber yarn embedded in cement mortar. Science and Engineering of Composite Materials, 18(3), pp. 181-186, 2011. DOI: 10.1515/SECM.2011.029.

[3] Lubej, S., Anžel, I., Jelušič, P., Kosec, L. \& Ivanič, A., The effect of delayed ettringite formation on fine grained aerated concrete mechanical properties. Science and Engineering of Composite Materials, 23(3), pp. 325-334, 2016. DOI: 10.1515/secm2012-0107.

[4] Lubej, S., Ivanič, A. \& Radosavljević, M., Possibility for strength improvement of concrete with delayed ettringite formation. Proceedings of the 1st International Conference on Structures and Architecture, pp. 1601-1607, 2010.

[5] Lubej, S., Ivanič, A., Rudolf, R. \& Anžel, I., Influence of delayed ettringite formation on the mechanical properties of aerated concrete. Materiali in Tehnologije, 46(6), pp. 573-579, 2012.

[6] Lubej, S. \& Ivanič, A., Influence of cure on the properties of polymer-modified mortars (Utjecaj njege na svojstva mortova s dodatkom polimera). Gradevinar, 59(9), pp. 779788, 2007.

[7] Lubej, S., Ivanič, A. \& Ivanovski, I., Structural impacts of vibrations during road construction. 17th International Congress on Sound and Vibration 2010, pp. 1648$1655,2010$.

[8] Lubej, S., Ivanic A., Toplak S. \& Lep, M., The effects of road traffic vibrations on historic buildings. 18th International Congress on Sound and Vibration 2011, pp. 1772-1779, 2011.

[9] Toplak S., Lubej S., Ivanič, A. \& Lep, M., Pavement quality, safety and vibrations. ICSV 2016 - 23rd International Congress on Sound and Vibration: From Ancient to Modern Acoustics, 2016.

[10] Lep, M., Lubej, S. \& Ivanic, A., Ground vibrations: A neglected external cost in the life cycle of transportation infrastructure? 8th International Conference on Environmental Engineering, ICEE 2011, pp. 942-947, 2011.

[11] Kravanja, S., Turkalj, G., Šilih, S. \& Žula, T., Optimal design of single-story steel building structures based on parametric MINLP optimization. Journal of Constructional Steel Research, 81, pp. 86-103, 2013. DOI: 10.1016/ j.jcsr.2012.11.008.

[12] Kravanja, S., Žula, T. \& Klanšek, U., Multi-parametric MINLP optimization study of a composite I beam floor system. Engineering Structures, 130, pp. 316-335, 2017. DOI: 10.1016/j.engstruct.2016.09.012.

[13] Viswanathan, J. \& Grossmann, I.E., A combined penalty function and outer approximation method for MINLP optimization. Computers and Chemical Engineering, 14(7), pp. 769-782, 1990. 